\title{
STUDIES OF THE PULMONARY AND SYSTEMIC ARTERIAL PRESSURE IN CASES OF PATENT DUCTUS ARTERIOSUS WITH SPECIAL REFERENCE TO EFFECTS OF SURGICAL CLOSURE ${ }^{1}$
}

\author{
By BOWEN E. TAYLOR,2 ALBERT A. POLLACK,2 HOWARD B. BURCHELL, \\ O. THERON CLAGETT, AND EARL H. WOOD
}

\author{
(From the Divisions of Medicine and Surgery, Mayo Clinic, and the Section on Physiology, \\ Mayo Foundation, Rochester, Minnesota)
}

(Submitted for publication November 3, 1949; accepted, March 6, 1950)

A patent ductus arteriosus has been found to shunt 4 to 19 liters of oxygenated blood from the aorta to the pulmonary artery each minute, representing 45 to 75 per cent of the output of the left ventricle (1). However, even with pulmonary blood flow of from two to four times the systemic flow, the pulmonary arterial pressure has been within normal limits in most cases in which measurements have been made $(2,3)$. These results are in agreement with data obtained by Cournand (4) which indicated that in normal man the flexibility of the pulmonary vessels is such that the flow through them can be increased two to three times without an appreciable increase in pulmonary arterial pressure.

It might be expected that closing a patent ductus arteriosus with a flow of such magnitude would cause a dramatic cardiovascular response. The lack of knowledge of the immediate changes in the circulodynamics during closure of a patent ductus arteriosus, and especially of the changes occurring in the pulmonary arterial pressure, led to study of these physiologic variables before, during and after surgical correction of this condition.

\section{METHODS}

Preoperative cardiac catheterization was performed in six of the patients. Pressures were recorded in the pulmonary artery, right ventricle and right atrium by means of a strain gauge manometer $(5,6)$ attached to the end of the cardiac catheter. The oxygen saturation of blood samples from the pulmonary artery, right ventricle and radial artery was determined by gasometric analysis in order to calculate the amount of blood flow through the patent ductus arteriosus. In six cases, it was also pos-

\footnotetext{
1 Abridgment of thesis submitted by Dr. Taylor to the Graduate School of the University of Minnesota in partial fulfillment of the requirements for the degree of Master of Science in Medicine.

2 Fellow in Medicine, Mayo Foundation.
}

sible to make an approximation of the percentage of the left ventricular output shunted through the patent ductus, by oxygen saturation determinations of blood samples taken from the pulmonary artery at the operation. One blood sample was taken before and another after closure of the patent ductus arteriosus. The blood sample drawn from the pulmonary artery after the ductus arteriosus had been closed was assumed to represent mixed venous blood. Blood samples were also taken from the radial artery to determine the oxygen saturation of the systemic arterial blood. Because the blood samples taken during the operation contained nitrous oxide and ether, the oxygen saturation was determined by means of a cuvette oximeter for whole blood $(7,8)$.

Before and after the operation for closure of the patent ductus arteriosus, direct arterial pressures, electrocardiogram and heart rate were recorded in some of the patients during rest in the supine position, standing at rest, walking 1.7 miles per hour for one minute and also during another one-minute period of walking 3 miles per hour. The pressures were recorded by an intraradial arterial needle connected by $30 \mathrm{~cm}$. of polythene tubing ${ }^{3}$ to a strain gauge manometer as shown in Figure 1. The electrocardiogram and instantaneous heart rate were recorded by means of a cardiotachometer (9). This procedure was also utilized to study the effect of exercise on the arterial pressure and heart rate in a series of normal subjects.

Photographic records of the radial arterial pressure, the pulmonary arterial pressure, electrocardiogram, instantaneous heart rate and respiration were made by means of a mobile oscillograph during the operation for closing of the ductus arteriosus (10). Both arterial pressures were recorded by means of strain gauge manometers (5).

During operation, after the patent ductus arteriosus had been isolated and ligatures had been placed loosely around it but not tied, the diameter and length of the ductus were measured by means of small calipers. The needle attached to the sterile strain gauge manometer used to measure the pulmonary pressures (Figure 2) was then inserted into the left pulmonary artery slightly

${ }^{3}$ Polythene tubing : inner diameter $=0.085$; outer diameter $=0.135$ inch, Surprenant Manufacturing Company, Boston, Massachusetts. 


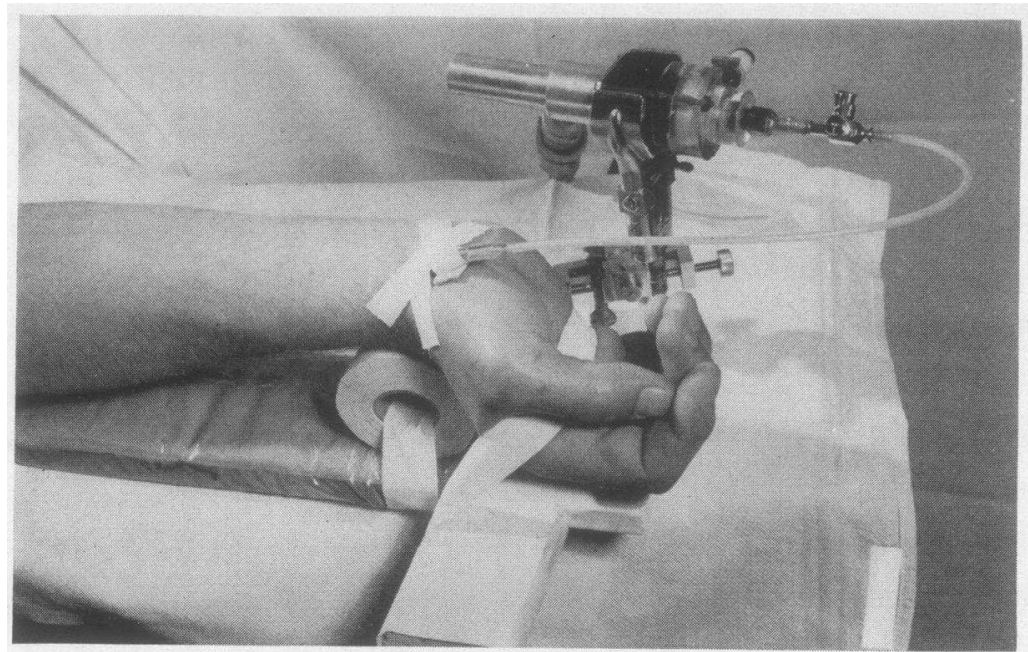

Fig. 1. Strain Gauge Manometer Assembly Úsed to Record Radial Akterial Pressures While the Subject Was Walking on a Treadmill.

distal to the ductus arteriosus. Simultaneous records of the radial and pulmonary arterial pressures were made while the ductus arteriosus was closed and opened by means of rubber covered surgical forceps.

Mean pressures were determined from the recorded pulse contours by planimetric measurement of at least a 10 second period of the continuous recording of the pressure. Values for systolic and diastolic pressure were obtained by averaging the values obtained for each pressure pulse during this same period.

\section{RESULTS}

In the group of seven patients with patent ductus arteriosus in whom arterial pressure was recorded continuously during exercise, the average pulse pressure while standing was $84 \pm 9^{*}$ (43 to

4 The number following the \pm sign is the standard error of the mean, $n=7$.
120) mm. of mercury as compared with the average value of $55 \pm 4$ (44 to 71 ) $\mathrm{mm}$. of mercury obtained in seven normal subjects. The increase of pulse pressure in cases of patent ductus arteriosus was associated with an average slight increase in systolic pressure and a small average decrease in diastolic pressure in comparison to the values obtained in normal subjects (Table I). Figure 3 is a blood pressure recording during exercise of a patient with a patent ductus arteriosus in whom the auscultatory fifth sound was found to be audible to zero pressure. The auscultatory pressures recorded at the time of the exercise test were: standing: 118/44; after walking 1.7 miles per hour for one minute: 120/40-0; and after walking 3 miles per hour for one minute: $118 / 40$

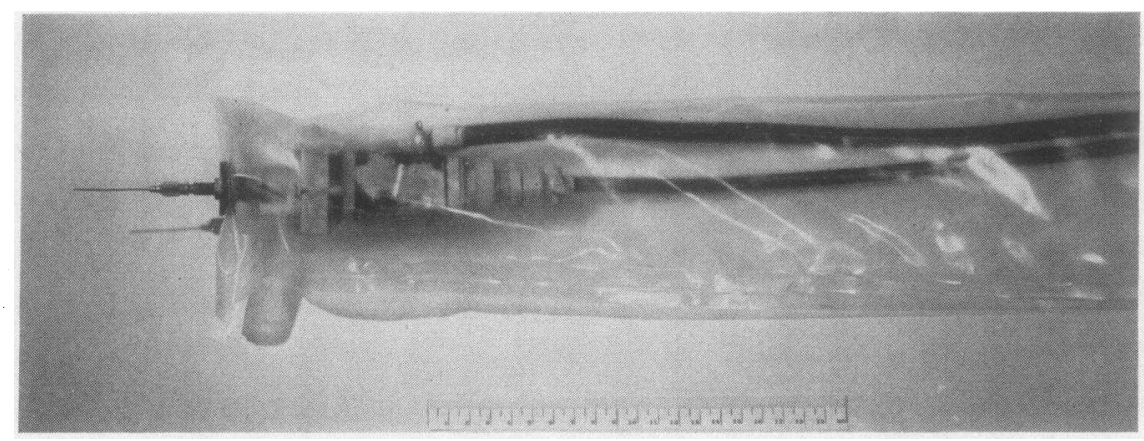

Fig. 2. Strain Gauge Manometer Assembly Used to Record Blood Pressures IN THE OPEN Thorax

The manometer is enclosed in a waterproof plastic sleeve to facilitate chemical sterilization. 
TABLE I

The effect of walking on intraradial blood pressure in normal subjects and patients with patent ductus arteriosus

\begin{tabular}{|c|c|c|c|c|c|c|c|c|c|c|}
\hline & & \multicolumn{3}{|c|}{ Standing at rest } & \multicolumn{3}{|c|}{$\begin{array}{c}\text { Walking } \\
1.7 \mathrm{~m} . / \mathrm{hr} .1 \mathrm{~min} .\end{array}$} & \multicolumn{3}{|c|}{$\begin{array}{c}\text { Walking } \\
3 \mathrm{~m} . / \mathrm{hr} .1 \mathrm{~min} .\end{array}$} \\
\hline & & Systolic & $\begin{array}{l}\text { Dias- } \\
\text { tolic }\end{array}$ & Ht. rate & Systolic & $\begin{array}{l}\text { Dias- } \\
\text { tolic }\end{array}$ & Ht. rate & Systolic & $\begin{array}{l}\text { Dias- } \\
\text { tolic }\end{array}$ & Ht. rate \\
\hline \multirow{2}{*}{$\begin{array}{l}\text { Patent ductus arteriosus } \\
\text { (7 cases) }\end{array}$} & Average & $\begin{array}{c}m m . H g \\
151\end{array}$ & $\begin{array}{c}m m . \mathrm{Hg} \\
66\end{array}$ & \begin{tabular}{|c|} 
beats $/$ min. \\
86
\end{tabular} & $\begin{array}{c}m m . H g \\
159\end{array}$ & $\begin{array}{l}\text { mm. } \mathrm{Hg} \\
\quad 67\end{array}$ & beats/min. & $\begin{array}{c}m m . \mathrm{Hg} \\
172\end{array}$ & $\begin{array}{c}m m . H g \\
69\end{array}$ & $\begin{array}{c}\text { beatsimin. } \\
109\end{array}$ \\
\hline & Range & $102-184$ & $56-75$ & $66-114$ & $116-210$ & $60-77$ & $78-114$ & $123-211$ & $61-83$ & $78-138$ \\
\hline \multirow{2}{*}{7 normal subjects } & Average & 133 & 78 & 87 & 149 & 75 & 94 & 150 & 73 & 99 \\
\hline & Range & $109-149$ & 64-94 & $78-102$ & $125-171$ & $62-85$ & $72-102$ & $135-173$ & $56-88$ & $84-120$ \\
\hline
\end{tabular}

28. Direct recording of arterial pressure, however, did not reveal any instance of an appreciable decrease in diastolic pressure during exercise in these patients. Actually a slight increase of both the systolic and diastolic pressures occurred associated with a marked increase in pulse rate (Table I). The changes in blood pressure produced in normal subjects by walking were similar
(Table I, Figure 4) as were the effects obtained in two of these patients two weeks after ligation of the ductus arteriosus (Figure 5). Small decreases in diastolic pressure during walking were frequently observed in the normal subjects.

Six patients with patent ductus arteriosus were studied preoperatively by means of cardiac catheterization. Calculations based on the Fick princi-

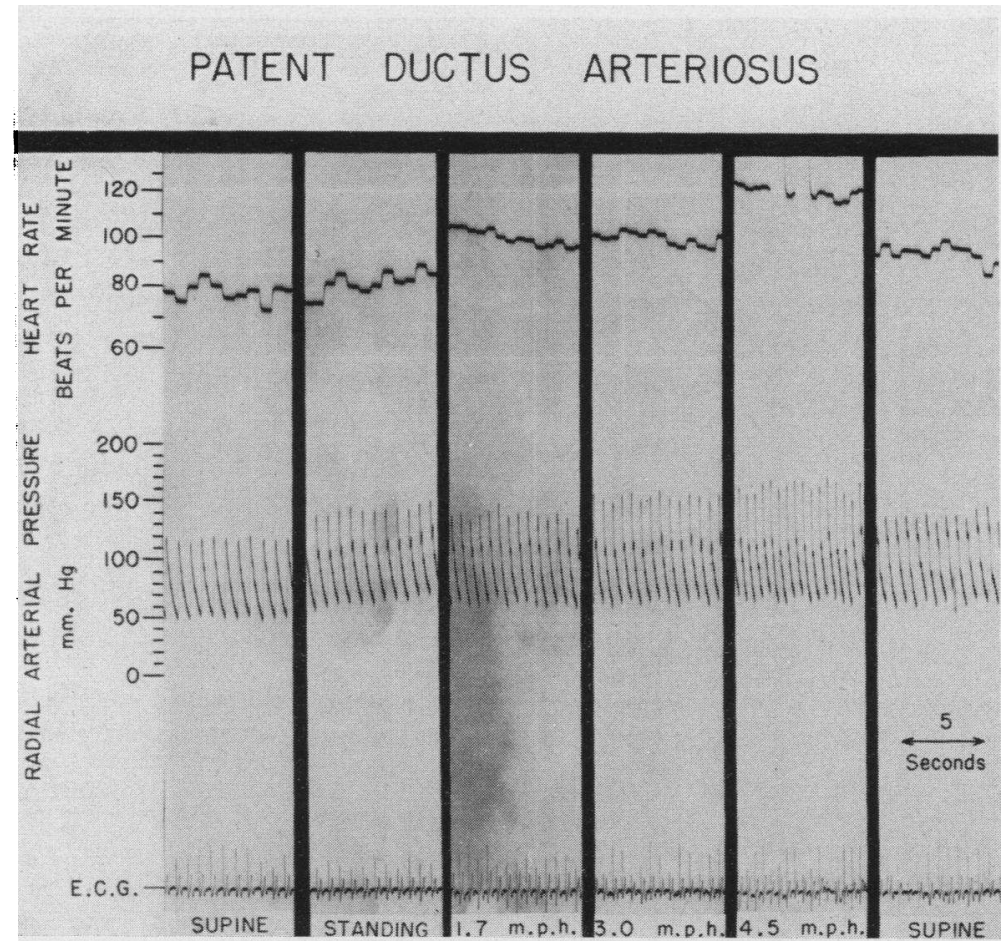

Fig. 3. The Effect of Walking on the Intraradial Arterial Pressure and Heart Rate in a Patient with a Patent Ductus Arteriosus

The successive panels were recorded during supine rest, standing at rest, walking $1.7,3.0$ and 4.5 miles per hour. 
TABLE II

Intraarterial pressures and blood flow as determined by cardiac catheterization in six patien's with patent ductus arteriosus

\begin{tabular}{|c|c|c|c|c|c|c|}
\hline Case & $\begin{array}{l}\text { Systemic } \\
\text { pressure }\end{array}$ & $\begin{array}{c}\text { Pul- } \\
\text { monary } \\
\text { pressure }\end{array}$ & $\begin{array}{c}\text { Systemic } \\
\text { blood } \\
\text { flow }\end{array}$ & $\begin{array}{l}\text { Pul- } \\
\text { monary } \\
\text { blood } \\
\text { flow }\end{array}$ & $\begin{array}{l}\text { Blood } \\
\text { flow } \\
\text { through } \\
\text { the } \\
\text { ductus }\end{array}$ & $\begin{array}{l}\text { Shunt as } \\
\text { per cent } \\
\text { of left } \\
\text { ventricular } \\
\text { output }\end{array}$ \\
\hline $\begin{array}{c}1 \\
2 \\
7 \\
12 \\
17 \\
18 \\
\text { Average }\end{array}$ & $\begin{array}{c}m m . H g \\
127 / 72 \\
117 / 54 \\
156 / 66 \\
124 / 76 \\
* \\
126 / 58 \\
130 / 65\end{array}$ & $\begin{array}{c}m m . H g \\
30 / 12 \\
37 / 22 \\
30 / 20 \\
25 / 10 \\
108 / 29 \\
29 / 20 \\
43 / 19\end{array}$ & $\begin{array}{c}\text { l. } / \text { min. } \\
5.1 \\
5.6 \\
6.5 \\
5.3 \\
2.9 \\
3.6 \\
4.8\end{array}$ & $\begin{array}{c}\text { l./min. } \\
8.1 \\
10.7 \\
24.2 \\
6.9 \\
5.4 \\
17.9 \\
12.2\end{array}$ & $\begin{array}{c}l . / \min . \\
3.0 \\
5.1 \\
17.7 \\
1.6 \\
2.5 \\
14.3 \\
7.4\end{array}$ & $\begin{array}{l}37 \\
48 \\
73 \\
23 \\
46 \\
80 \\
51\end{array}$ \\
\hline
\end{tabular}

* Direct systemic arterial pressures not recorded.

ple (11) made it possible to determine the approximate cardiac output and the magnitude of flow through the patent ductus arteriosus in these cases (Table II). The average pulmonary pressure recorded in these cases was $43 \mathrm{~mm}$. of mercury systolic and 19 diastolic. The systemic blood flow averaged 4.8 liters, the pulmonary blood flow 12.2 liters and the amount of flow through the ductus arteriosus was approximately 7.4 liters per minute. The average shunt through the ductus arteriosis in these six cases was 51 (23 to 80 ) per cent of the left ventricular output.

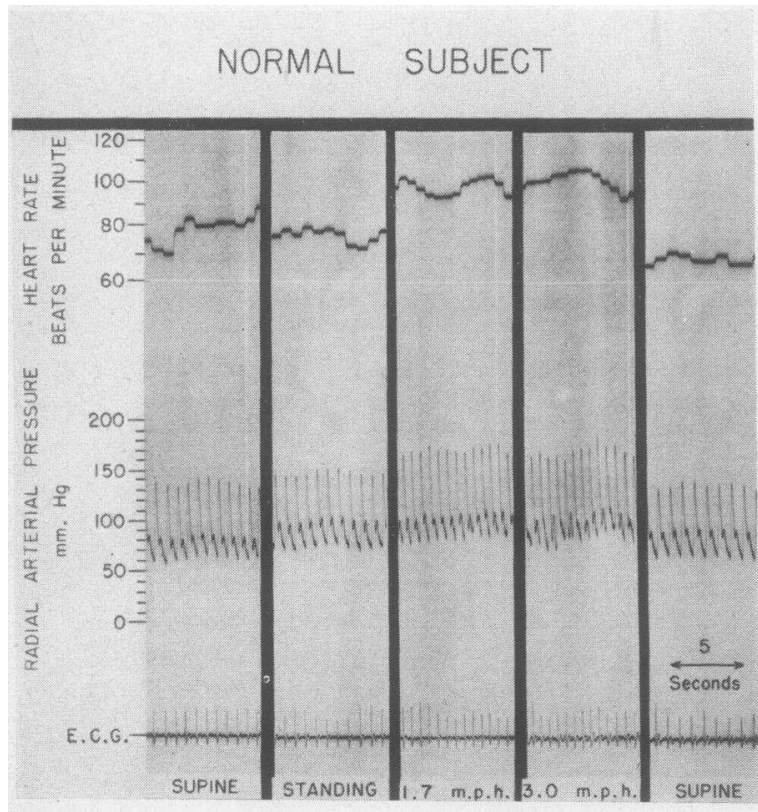

Fig. 4. The Effect of Walking on the Intraradial Arterial Pressure and Heart Rate in a Normal Subject

\section{AFTER LIGATION OF PATENT DUCTUS}

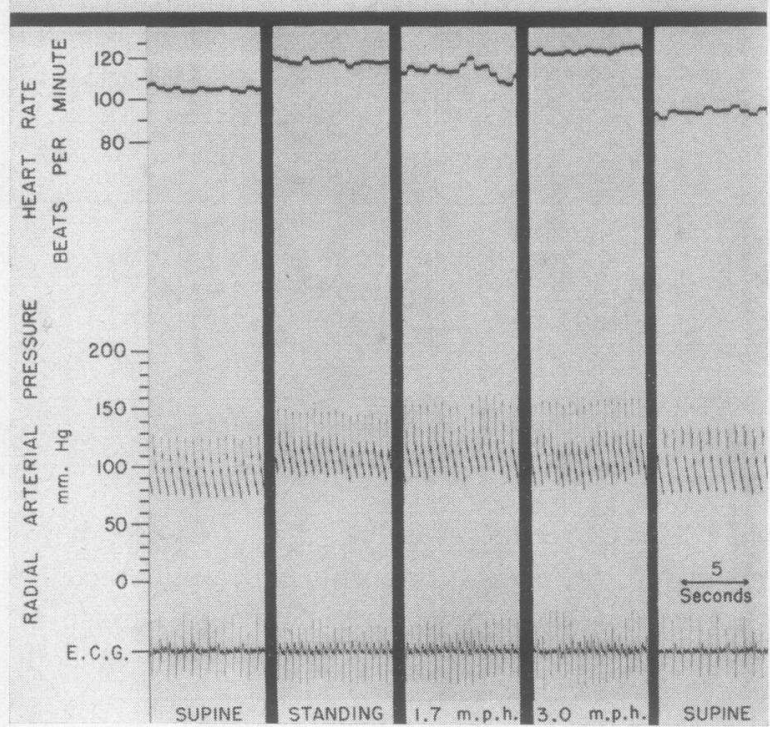

Fig. 5. The Effect of Walking on the Intraradial Arterial Pressure and Heart Rate in a PAtient After Ligation of a Patent Ductus Arteriosus

This recording was obtained on the same patient more than two weeks after the record shown in Figure 3 and two weeks after surgical obliteration of the ductus arteriosus.

The oxygen saturation of the blood samples withdrawn during operation from the pulmonary artery before and after closure of the patent ductus arteriosus and also from the radial artery was used to estimate the percentage of left ventricular output shunted through the ductus arteriosus. ${ }^{5}$ In the six cases in which these blood samples were obtained, the shunt through the patent ductus averaged 37 (27 to 52) per cent of the left ventricular output.

The diameter and length of the ductus arteriosus were measured at the time of operation in 15 cases.

5 The following formula was used to calculate the shunt through the patent ductus arteriosus:

$$
\text { Ductal flow }=\frac{100(\mathrm{PA}-\mathrm{RV})}{(\mathrm{A}-\mathrm{RV})}
$$

where ductal flow was calculated as the cubic centimeters per $100 \mathrm{cc}$. of the left ventricular output, A was the oxygen saturation of the systemic arterial blood, RV was the oxygen saturation of the mixed venous blood (oxygen saturation of blood in the pulmonary artery after closure of the ductus) and PA was the oxygen saturation of the blood in the pulmonary artery when the ductus was open. 
TABLE III

Immediate change of pressure in radial and pulmonary arteries produced by closure of a patent ductus arteriosus in 15 patients

\begin{tabular}{|c|c|c|c|c|}
\hline & \multicolumn{2}{|c|}{ Radial artery } & \multicolumn{2}{|c|}{ Pulmonary artery } \\
\hline & Average & Range & Average & Range \\
\hline Systolic & $\begin{array}{c}m m . H g \\
8.7 \\
\pm \quad 1.9^{*}\end{array}$ & $\begin{array}{l}m m . H g \\
2 \text { to } 26\end{array}$ & $\begin{array}{c}m m . H g \\
-3.0 \\
\pm 1.0\end{array}$ & $\begin{array}{c}m m . H g \\
+2.2 \text { to }-10\end{array}$ \\
\hline Diastolic & $\begin{array}{r}10.6 \\
\pm \quad 1.9\end{array}$ & 5 to 31 & $\begin{array}{l}-5.1 \\
\pm 0.9\end{array}$ & -1.1 to -10 \\
\hline Mean & $\begin{array}{r}10.8 \\
\pm \quad 1.7\end{array}$ & 4 to 25 & $\begin{array}{l}-4.2 \\
\pm 0.8\end{array}$ & +0.5 to -10.9 \\
\hline
\end{tabular}

* The number after the \pm sign is the standard error of the mean, $\mathrm{n}=15$.

The average outside diameter of the ductus arteriosus in situ was $10 \mathrm{~mm}$., range 7.5 to $13 \mathrm{~mm}$. The approximate length of the ductus averaged 8 (6 to 10$) \mathrm{mm}$. In all but one case the outside diameter exceeded the length of the ductus.

Satisfactory records of radial and pulmonary arterial pressure were obtained in 15 patients. The immediate changes in the radial and pulmonary arterial pressures produced by closure of a patent ductus arteriosus are summarized in Table III. The systolic, diastolic and mean radial arterial pressures increased in every instance when the ductus was closed. The average increase in the systolic radial pressure was 9 , the diastolic was 11 and the mean pressure was $11 \mathrm{~mm}$. of mercury.
The systolic and diastolic pulmonary pressures decreased with one exception. The average decrease in pulmonary pressure was systolic 3 and diastolic $5 \mathrm{~mm}$. of mercury. The mean pulmonary arterial pressure decreased an average of $4 \mathrm{~mm}$. of mercury. These average values were found to be statistically significant ( $p$ values less than $0.001)$.

The recorded pulse rate and respiration showed no immediate changes coincident with the closure of the patent ductus arteriosus in these 15 patients. Four records were obtained during the application of pressure on both carotid sinuses of three of these patients at the time of the operation while the patient was under the nitrous oxide, oxygen and ether anesthesia. No slowing of the heart rate was produced.

The relationship between systemic and pulmonary arterial pressures, the size of the ductus arteriosus and the relative blood flow through a patent ductus arteriosus is shown in Table IV. This table includes the estimations of blood flow through the ductus as determined from the six cardiac catheterizations and the per cent shunt determined from samples of blood obtained during the operation for closure of the patent ductus arteriosus.

The average intraradial pressure was systolic 130 and diastolic $72 \mathrm{~mm}$. of mercury. The average pulmonary arterial pressure was systolic 40 and diastolic $19 \mathrm{~mm}$. of mercury. In this com-

TABLE IV

Relationship of systemic and pulmonary arterial pressures to the size and relative blood flow through a patent ductus arteriosus (12 patients)

\begin{tabular}{|c|c|c|c|c|c|c|c|}
\hline \multirow{2}{*}{ Case } & \multicolumn{2}{|c|}{ Direct systemic pressure } & \multicolumn{2}{|c|}{ Pulmonary arterial pressure } & \multicolumn{2}{|c|}{ Size of ductus } & \multirow{2}{*}{$\begin{array}{l}\text { Shunt as } \\
\text { per cent } \\
\text { of left } \\
\text { ventricular } \\
\text { output }\end{array}$} \\
\hline & Systolic & Diastolic & Systolic & Diastolic & Length & $\begin{array}{l}\text { Outside } \\
\text { diameter }\end{array}$ & \\
\hline $\begin{array}{c}1^{*} \\
2^{*} \\
7^{*} \\
10 \\
11 \\
12^{*} \\
13 \\
14 \\
15 \\
16 \\
17^{*} \\
18^{*} \\
\text { Average }\end{array}$ & $\begin{array}{c}m m . H g \\
127 \\
117 \\
156 \\
128 \\
113 \\
124 \\
88 \\
128 \\
159 \\
165 \\
126 \\
130\end{array}$ & $\begin{array}{c}m m . H g \\
72 \\
54 \\
66 \\
71 \\
74 \\
76 \\
53 \\
81 \\
95 \\
92 \\
58 \\
72\end{array}$ & $\begin{array}{c}m m . H g \\
30 \\
37 \\
30 \\
48 \\
35 \\
25 \\
28 \\
30 \\
37 \\
39 \\
108 \\
29 \\
40\end{array}$ & $\begin{array}{c}m m . H g \\
12 \\
22 \\
20 \\
16 \\
23 \\
10 \\
11 \\
17 \\
21 \\
27 \\
29 \\
20 \\
19\end{array}$ & $\begin{array}{c}m m . \\
8 \\
10 \\
6.9 \\
7 \\
10 \\
7.5 \\
9.5 \\
9 \\
8 \\
\\
8.4 .\end{array}$ & $\begin{array}{l}m m . \\
10.5 \\
12 \\
7.6 \\
9.3 \\
13 \\
10 \\
10 \\
8 \\
9 \\
\\
9.9\end{array}$ & $\begin{array}{l}37 \\
48 \\
73 \\
29 \\
52 \\
23 \\
29 \\
27 \\
41 \\
42 \\
46 \\
80 \\
44\end{array}$ \\
\hline
\end{tabular}

* Values determined by cardiac catheterization. All other values determined at operation. 
bined group of cases, the shunt through the ductus averaged 44 per cent of the left ventricular output. No consistent relationship was found to exist between the flow through the ductus and the pressure gradient across it (coefficient of correlation $=0.01$ ), nor between the flow and the diameter of the ductus (coefficient of correlation $=0.15$ ).

\section{COMMENT}

The decrease in diastolic pressure during exercise in cases of patent ductus arteriosus has been used as a diagnostic sign and has been thought to be indicative of a large ductus $(1,2,12-14)$. That there was no significant decrease in diastolic pressure during exercise when recorded by the direct technic seems to indicate that some changes determined by auscultation are primarily related to the errors inherent in the indirect method of recording blood pressure $(15,16)$. It is suspected that the error is greatest in conditions associated with an increased pulse pressure.

The determination of the amount of shunt through a patent ductus arteriosus is admittedly an approximation. A large degree of error can be introduced into such determinations by the tip of the cardiac catheter or the arterial needle being in the stream of oxygenated blood entering the pulmonary artery from the ductus. Another recognized source of error in such calculations based on the blood samples taken during operation is that the samples were taken from the left pulmonary artery, and since the left lung was partially collapsed, the flow through the left artery would be expected to differ from the flow through the right pulmonary artery. Errors of this type cannot be avoided with certainty in individual cases; however, it is believed that the magnitude of the average values is of significance.

No consistent relationship was apparent between the flow through the ductus arteriosus and the pressure gradient across it nor between the flow and the outside diameter of the ductus arteriosus. The most consistent correlation was obtained by correlating the blood flow through the ductus arteriosus with the product of the radius of the ductus arteriosus squared and the square root of the aorta to pulmonary artery pressure gradient, as in the formula for fluid flow through a short tube $(17,18)$. However, this did not follow in every case. The lack of a constant rela- tionship between the inside and outside diameter of a patent ductus arteriosus and errors in estimation of ductal flow are very probably important factors in the variability obtained.

Because of the clinical impression that the pulse pressure is indicative of the size of the ductus and the amount of the shunt, an attempt was made to correlate these variables. There was a questionable positive correlation when the auscultatory pulse pressure was related to the percentage of left ventricular output shunted through the ductus. A somewhat better correlation was obtained by using the direct pressures recorded at the time of measurement of the shunt through the ductus and expressing the pulse pressure as percentage of the diastolic pressure (Figure 6).

Numerous studies have been reported, indicating that after a patent ductus arteriosus had been closed surgically there was postoperatively a rise in the systemic diastolic pressure $(2,19-21)$, a reduction in the pulmonary flow $(2,20)$, and a reduction in size of the dilated heart (20-22). Most of the reports emphasize the rise in diastolic pressure and very little change was noted in the systolic pressure. Crafoord, Mannheimer, and Wiklund (23) noted a rise in systolic pressure in some cases when the ductus arteriosus was closed but the pressure returned to normal in a few minutes.

Our data indicated that the increased systolic pressure coincident with closure of a ductus arteriosus was almost as great as the diastolic rise recorded in these patients. However, this was an

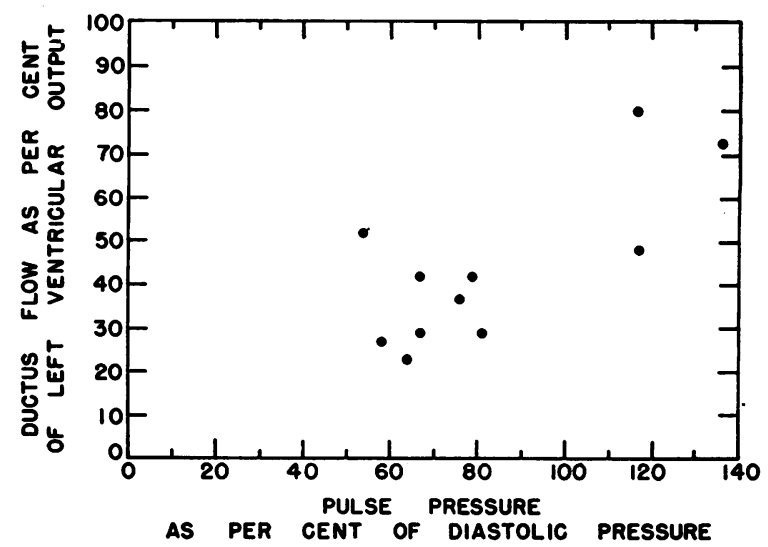

Fig. 6. The Relationship Between Systemic Pulse Pressure and the Relative Blood Flow through a Patent Ductus Arteriosus 
TABLE V

A comparison of the pulmonary arterial pressure recorded through a cardiac catheter prior to operation with the pressure recorded by puncture of the pulmonary artery during thoracotomy for ligation of $a$ patent ductus arteriosus

\begin{tabular}{|c|c|c|}
\hline \multirow[b]{2}{*}{ Case } & \multicolumn{2}{|c|}{ Pulmonary arterial pressure recorded } \\
\hline & $\begin{array}{l}\text { Preoperatively } \\
\text { through a } \\
\text { cardiac catheter }\end{array}$ & $\begin{array}{l}\text { During thoracotomy } \\
\text { by means of pulmonary } \\
\text { arterial puncture }\end{array}$ \\
\hline $\begin{array}{r}1 \\
3 \\
7 \\
12\end{array}$ & $\begin{array}{r}m m . H g \\
30 / 14 \\
112 / 66 \\
30 / 20 \\
25 / 10\end{array}$ & $\begin{array}{r}m m . H g \\
38 / 18 \\
113 / 70 \\
45 / 22 \\
28 / 17\end{array}$ \\
\hline
\end{tabular}

immediate change and cannot be applied to the postoperative clinical status of the patients.

The pulmonary arterial pressures (Table II) recorded through the cardiac catheter averaged $43 \mathrm{~mm}$. of mercury systolic and 19 diastolic. If the one case of severe pulmonary hypertension were excluded from the group, the average would be $30 / 17$, the upper limits for normal (24). In four cases it was possible to compare the pulmonary arterial pressures recorded preoperatively through a cardiac catheter with the pressures recorded by direct arterial puncture during thora- cotomy for closure of the patent ductus arteriosus (Table V).

That the pulmonary arterial pressures recorded during operation were uniformly higher than the pressures obtained preoperatively could have resulted from several factors such as anesthesia, the open thorax, partial collapse of the left lung; also systemic instrumental errors in recording pressures through a cardiac catheter cannot be absolutely excluded (6).

The change in the pressure in the pulmonary artery after surgical closure of a patent ductus arteriosus has been determined in only a few instances. Dexter and co-workers (25) have reported preoperative and postoperative catheterization studies in a patient with patent ductus arteriosus, in whom the pulmonary arterial pressure was $63 / 35 \mathrm{~mm}$. of mercury with ductus open and increased to $80 / 45$ after the ductus had been closed. In another case, reported by Dexter (26), however, preoperative pulmonary arterial pressure of $48 / 33 \mathrm{~mm}$. of mercury decreased after surgical closure of a patent ductus arteriosus to $32 / 10 \mathrm{~mm}$. of mercury.

In the present study closure of the ductus arteriosus produced an immediate slight increase in

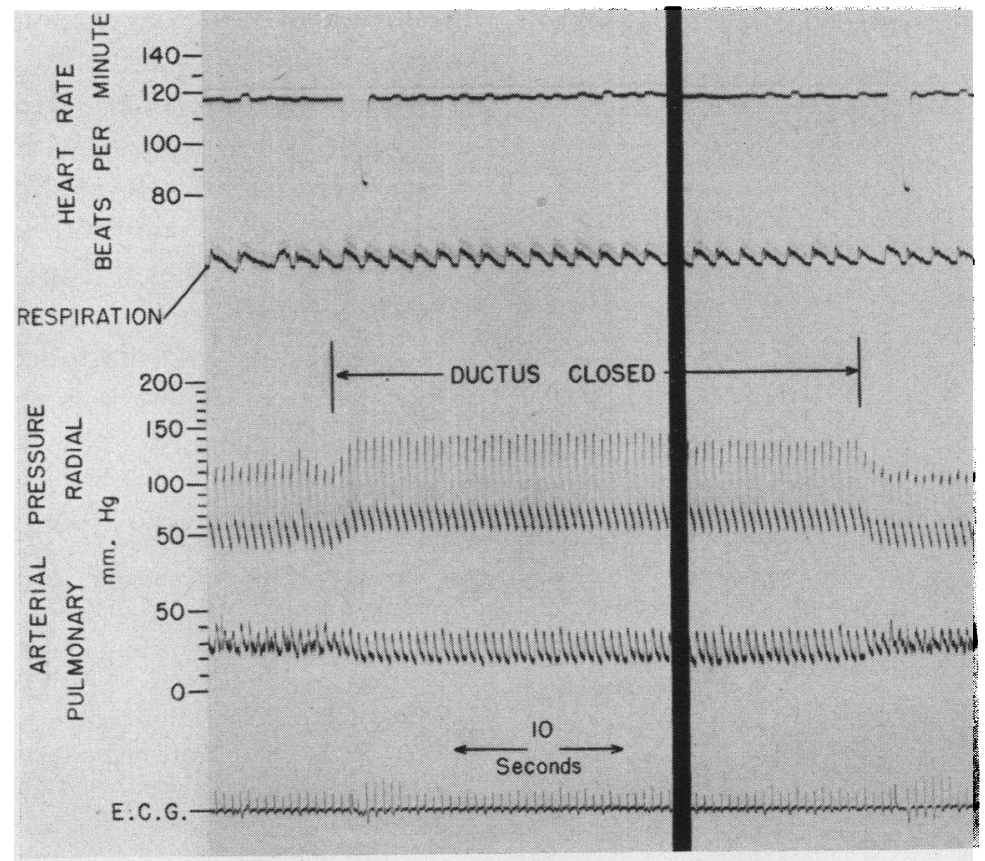

Fig. 7. The Effect of Temporary Closure of a Patent Ductus Arteriosus on the Systemic and Pulmonary Arterial Pressure 
the systemic blood pressure and a slight decrease in the pulmonary arterial pressure (Figures 7 and 8). These changes could be repeated at will by opening or closing the ductus with rubber covered surgical forceps. That these changes were both immediate and simultaneous supports the belief that the changes were primarily a direct hydrodynamic effect. Although the changes in the pulmonary arterial pressures were small, the relative changes, if they are considered on a percentage basis, are as great or greater than those in the systemic circulation. That there were no dramatic changes in the pulmonary arterial pressures when the ductus arteriosus was closed probably is related to the great flexibility of the pulmonary vessels and the low peripheral resistance of the pulmonary system in the patients studied.

The present studies (18) have been for the most part confirmed by similar studies conducted in another laboratory (27).

The bradycardic response seen with closing of a peripheral arteriovenous fistula was not observed coincident with the temporary occlusion of a patent ductus arteriosus (Figures 7 and 8). That there was no change in heart rate may have been due to the effects of anesthesia on cardioregulatory mechanisms as suggested by the fact that the three patients tested during the period of

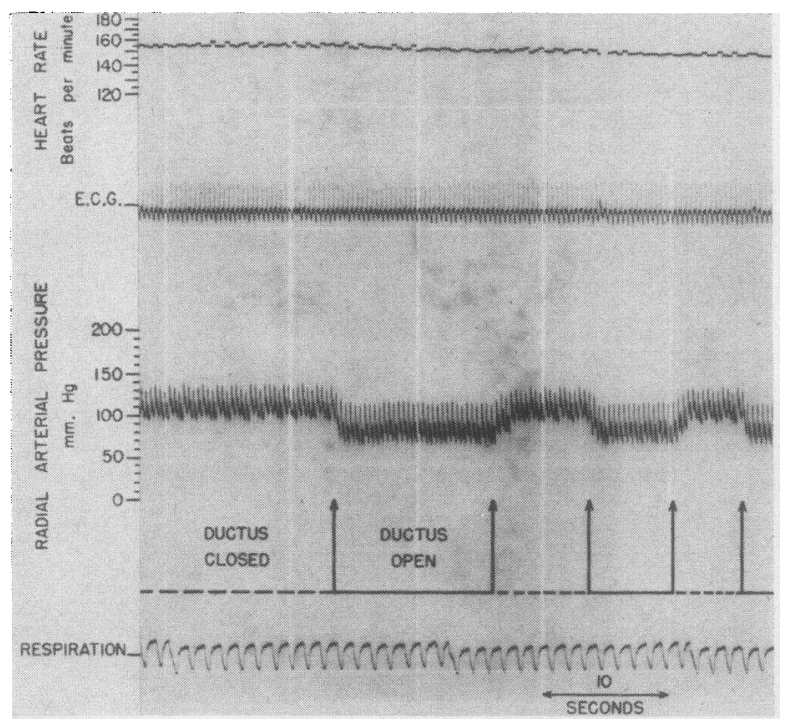

Fig. 8. The Effect on Systemic Arterial Pressure and Heart Rate Produced by Intermittent Closure of a Patent Ductus Arteriosus anesthesia showed no response to pressure on the carotid sinus.

\section{SUM MARY}

In six patients in whom preoperative cardiac catheterization studies were performed, the average flow through the patent ductus arteriosus was calculated to be 7.4 ( 1.6 to 17.7 ) liters per minute.

Calculations based on the oxygen saturation of systemic arterial, pulmonary arterial and mixed venous blood samples obtained in 12 patients indicated that the average flow through the patent ductus arteriosus was 44 (23 to 80 ). per cent of the left ventricular output. The outside diameter of the ductus arteriosus in nine of these cases averaged 9.9 (7.6 to 13 ) $\mathrm{mm}$.

Continuous, direct, radial arterial pressures in seven patients with a patent ductus arteriosus and in seven normal subjects recorded during standing at rest and walking 1.7 and 3 miles per hour showed on the average that the patients had a higher pulse pressure than the normal subjects, a moderately increased systolic pressure and a slightly decreased diastolic pressure. The changes in blood pressure produced by exercise were similar in patients before and after ligation of the ductus arteriosus and for practical purposes not different from those obtained in normal subjects. Exercise did not produce a decrease in diastolic pressure in these cases.

The average pulmonary arterial pressures measured in 16 of the patients with patent ductus arteriosus were slightly elevated above the values reported for normal subjects.

Closure of a patent ductus arteriosus in 15 patients produced an immediate increase in the systemic systolic and diastolic arterial pressure in every instance. There was also a significant, immediate decrease in the pulmonary arterial pressure.

\section{BIBLIOGRAPHY}

1. Burwell, C. S., Eppinger, E. C., and Gross, R. E., The signs of patent ductus arteriosus considered in relation to measurements of circulation. $\mathrm{Tr}$. A. Am. Physicians, 1940, 55, 71.

2. Eppinger, E. C., Burwell, C. S., and Gross, R. E., Effects of patent ductus arteriosus on the circulation. J. Clin. Invest., 1941, 20, 127.

3. Vandam, L. D., Bing, R. J., and Gray, F. D., Jr., Physiological studies in congenital heart disease; measurements of the circulation in five selected cases. Bull. Johns Hopkins Hosp., 1947, 81, 192. 
4. Cournand, A., Recent observations on the dynamics of the pulmonary circulation. Bull. New York Acad. Med., 1947, 23, 27.

5. Lambert, E. H., and Wood, E. H., The use of a resistance wire, strain gauge manometer to measure intraarterial pressure. Proc. Soc. Exper. Biol. \& Med., 1947, 64, 186.

6. Lambert, E. H., and Jones, R. E., The characteristics of a resistance-wire manometer for measuring blood pressure in cardiac catheterization studies. Proc. Staff Meet., Mayo Clin., 1948, 23, 487.

7. Groom, D., Wood, E. H., Burchell, H. B., and Parker, R. L., The application of an oximeter for whole blood to diagnostic cardiac catheterization. Proc. Staff Meet., Mayo Clin., 1948, 23, 601.

8. Wood, E. H., The oximeter, in: Glasser, O., Medical Physics. The Year Book Publishers, Inc., 1950, Vol. II, p. 664.

9. Sturm, R. E., and Wood, E. H., An instantaneous recording cardiotachometer. Rev. Scient. Instruments, 1947, 18, 771.

10. Hallenbeck, G. A., Wood, E. H., and Clagett, O. T., Apparatus for recording physiologic variables during operations on man, with observations on changes of blood pressure during resection for coarctation of the aorta. S. Clin. North America, 1948, 28, 851.

11. Best, C. H., and Taylor, N. B., The Physiological Basis of Medical Practice. Ed. 2, Williams \& Wilkins Company, Baltimore, 1939.

12. Hubbard, J. P., The diagnosis and evaluation of compensated and uncompensated patency of the ductus arteriosus. J. Pediat., 1943, 22, 50.

13. Gilchrist, A. R., Patent ductus arteriosus and its surgical treatment. Brit. Heart J., 1945, 7, 1.

14. Vesell, H., and Kross, I., Patent ductus arteriosus with subacute bacterial endarteritis; diagnosis and indications for operation. Arch. Int. Med., 1946, 77, 659.

15. Steele, J. M., Comparison of simultaneous indirect (auscultatory) and direct (intra-arterial) measurements of arterial pressure in man. J. Mt. Sinai Hosp., 1942, 8, 1042.
16. Brown, G. E., Pollack, A. A., Taylor, B. E., and Wood, E. H., Unpublished data.

17. Vennard, J. K., Elementary Fluid Mechanics. Ed. 2, John Wiley \& Sons, Inc., New York, 1947.

18. Taylor, B. E., Pollack, A. A., Burchell, H. B., Clagett, O. T., and Wood, E. H., Studies of the pulmonary and systemic arterial pressure in cases of patent ductus arteriosus with special reference to effects of surgical ligation. Am. J. Physiol., 1948, 155, 472.

19. Bullock, L. T., Jones, J. C., and Dolley, F. S., The diagnosis and the effects of ligation of the patent ductus arteriosus; a report of eleven cases. J. Pediat., 1939, 15, 786.

20. Gross, R. E., Surgical Treatment for Abnormalities of the Heart and Great Vessels. Charles C. Thomas, Springfield, Illinois, 1947.

21. Winsor, T., and Burch, G. E., Congenital patent ductus arteriosus; a therapeutically reversible type of heart disease. South. M. J., 1945, 38, 132.

22. Fitts, C. H., Arterio-venous communications. Roy. Melbourne Hosp. Clin. Rep., 1944, 15, 97.

23. Crafoord, C., Mannheimer, E., and Wiklund, T., The diagnosis and treatment of patent ductus arteriosus (Botalli) in connection with 20 operated cases. Acta chir. Scandinav., 1944, 91, 97.

24. Cournand, A., Lauson, H. D., Bloomfield, R. A., Breed, E. S., and Baldwin, E. de F., Recording of right heart pressures in man. Proc. Soc. Exper. Biol. \& Med., 1944, 55, 34.

25. Dexter, L., Haynes, F. W., Burwell, C. S., Eppinger, E. C., Sosman, M. C., and Evans, J. M., Studies of congenital heart disease. III. Venous catheterization as a diagnostic aid in patent ductus arteriosus, tetralogy of Fallot, ventricular septal defect, and auricular septal defect. J. Clin. Invest., 1947, 26, 561 .

26. Dexter, L., Venous catheterization of the heart; results, interpretations, and value. Radiology, 1947, 48, 451.

27. Grover, R. F., Swan, H., II, and Maaske, C. A., Pressure changes in the pulmonary artery and aorta before and after ligation of the patent ductus arteriosus. Federation Proc., 1949, 8, 63. 